\title{
Call the midwife. Health personnel and mortality in Norway 1887-1920
}

\author{
Andreas Kotsadam ${ }^{1} \cdot$ Jo Thori Lind ${ }^{2} \oplus \cdot$ Jørgen Modalsli ${ }^{3,4}$
}

Received: 30 July 2020 / Accepted: 22 March 2021 / Published online: 18 May 2021

(c) The Author(s) 2021

\begin{abstract}
At the turn of the twentieth century, Norway, like many other countries, experienced a decrease in mortality and a substantial increase in the number of health personnel. In order to assess how these changes were connected, we investigate the relationship between health personnel and mortality using data at the medical district level $(N=106)$ covering a period of 34 years. We find a large and robust effect of midwives on reduced maternal mortality in rural areas, but no effect in urban areas. No clear effect is found for other types of health personnel or on infant mortality. The results demonstrate the important role played by public health investments during the period.
\end{abstract}

Keywords Health policy $\cdot$ Public service provision $\cdot$ History $\cdot$ Mortality

JEL Classification $\mathrm{H} 41 \cdot \mathrm{I} 18 \cdot \mathrm{N} 33$

\section{Introduction}

During most of human history, life expectancy has been low and maternal and child mortality have been high. Pregnancy and child bearing are major determinants of female health, today particularly in poor countries. The World Health Organization (2019) estimates that about 295,000 women still die every year in connection with child birth. The changes to life expectancy that came in the late 19th and early 20th century in the Western world were dramatic, and their reasons are suggested to have been improved material living standards, better access to health care, and

Jo Thori Lind

j.t.lind@econ.uio.no

1 Ragnar Frisch Centre for Economic Research, Oslo, Norway

2 Department of Economics, University of Oslo, Oslo, Norway

3 Oslo Business School, Oslo Metropolitan University, Oslo, Norway

4 Research Department, Statistics Norway, Oslo, Norway 
improvements in medicine (Deaton 2013). However, a more precise assessment of the historical effect of particular changes in health policies is not feasible without conducting an analysis with a research design suitable for causal inference. This is the purpose of the present paper.

Norway had a comprehensive, yet rudimentary public health system at an early point in time, and experienced large declines in mortality rates starting in the early 19th century. Although the country was among the first to enter the demographic transition and see marked drops in infant mortality (Pitkänen 2002; Edvinsson et al. 2008), mortality rates in the late 19th century were still at par with most present day African countries. However, from the 1880 s onward, there was a near continuous fall in mortality (Backer 1961).

In this paper, we investigate the role of health personnel for the improvement in health outcomes in Norway. To identify the effect of enhanced access to medical personnel, we utilize the fact that the roll-out of personnel at the local level was uneven and staggered. This implies that we can flexibly control for a vast array of other potential confounding variables. We find that the increase in the number of midwives is robustly associated with a large decrease in maternal mortality in rural areas. This likely reflects improved access to antiseptics and knowledge of hygiene disseminated by the midwives. In contrast, the distribution of medical doctors and other medical personnel shows little association with improvements in other health outcomes. There is also a weaker association between the number of midwives and reductions on neonatal mortal. Beyond this, we find no robust association with other types of mortality. In sum, a clear picture emerges, showing that midwives have a causal effect on reducing maternal mortality.

Our main identifying assumption is that there are no other changes in our areas that coincide precisely with the changes in health personnel-conditional on area and year fixed effects and area specific time trends. While such an assumption can never be proven, we believe that such coincidences are unlikely. For instance, we do not find any effects on "placebo" outcomes that should not be affected and we do not find effects directly before the health personnel change. In addition, the results are robust for controlling for poverty levels.

The data used in this analysis are obtained from comprehensive annual reports on the health conditions in Norway. We observe the number of health personnel and various health outcomes at the medical district level annually from 1887 to 1920 and use this to study local variation in welfare provision within Norway using panel data techniques. While the present-day Norwegian welfare state has a strong emphasis on equal provision of services throughout the country, this was not always the case. At the turn of the twentieth century, when the number of social insurance and health initiatives expanded fast, provision was predominantly at either the occupation or the local level. The roll-out of the Norwegian welfare state at the local level offers a setting where we can investigate the emergence and consequences of welfare state policies.

The effect of the expansion of midwifery on health and mortality has been explored both in historical perspective in affluent countries and in contemporary perspective in poorer countries. But to the best of our knowledge, there is no previous study on the effects of health personnel on mortality over such a long time period 
on such a fine level of aggregation. Andersson et al. (2000) study infant mortality using nineteenth-century micro-data from northern Sweden. They document that births where midwives were present had lower incidence of infant mortality. However, the paper is mostly descriptive and in an epidemiological tradition. The most similar paper to ours is a working paper by Pettersson-Lidbom (2015), who investigates the effects of midwives on maternal and infant mortality using yearly data from 25 Swedish regions between the years 1830 and 1894. He finds that increasing the number of trained midwives decreases maternal mortality. Our study covers a different country and a later time period. Most importantly, though, the data used here are at a much finer geographical level. This is potentially important as there is large variation within regions. We are also able to control for poverty levels using local data on poverty support.

Anderson et al. (2020) use the introduction of midwife licensing in the early 20th century US in a difference in differences setup to identify the effect of professional birth help compared to informal assistance. Using variation at the state level, they find a strong decline in maternal mortality, but only quite modest effects on infant mortality. Lazuka (2018) find that there are also long-term positive health effects on the children that are delivered in births assisted by midwives.

Moehling and Thomasson $(2012,2014)$ study the effects of the US Sheppard-Towner program, whereby federal matching money for public health education of mothers was granted during a period in the 1920s. They find that particularly interventions that provided one-on-one contact and home visits by nurses had a substantial effect on reducing infant mortality. Wüst (2012) confirm this finding in her study of the effect of the gradual roll-out of the Danish home visit program, where there is a quite clear positive impact on infant survival rates. These studies only use data from urban areas, though. As our study reveals, patterns may differ between urban and rural areas.

In a contemporary setting, Østby et al. (2018) show that maternal care is negatively associated with maternal deaths in 31 African countries. However, comparing mortality rates across countries in repeated cross sections does not allow for causal interpretations. In particular, there are so many other differences across countries and time periods that may affect both mortality and access to health personnel. Others have therefore analyzed the relationship within countries. One case that has received quite some attention is Indonesia's Midwife in the Village program, which increased the number of rural midwives more than tenfold during the 1990s. Frankenberg and Thomas (2001) find that this improved health outcomes of women in reproductive age, but not men or older women, and Frankenberg et al. (2005) find positive impact on child health. However, Triyana (2016) find that the program did not have long-term effects. Apart from the program in Indonesia, there are a few studies using a research design suitable for causal inference to study-related outcomes.

In contrast to our findings, there are studies showing an effect of increased access to medical doctors. Liebert and Mäder (2020) use the discrimination of Jewish physicians in pre-war Germany to identify the effect of physicians on mortality. They find an effect on infant and perinatal mortality. Lazuka et al. (2016) find that establishment of isolation hospitals combined with employment of midwives 
reduced infant and child mortality. They use panel data from parishes in southern Sweden to estimate a difference in difference model. Thomasson and Treber (2008) study the shift of child birth from homes to hospitals, using data on US cities. They find that until the 1930s, maternal mortality rates are comparable in hospitals and homes. Only with the introduction of sulfa drugs in the 1930 are hospitals able to provide better circumstances. In a contemporary setting, Cesur et al. (2017) analyze the gradual expansion of the Turkish Family Medicine Program, which provided increased access to physicians. They find a clear decline in infant mortality. Methodologically, our paper also resembles Bailey and Goodman-Bacon (2015), who study the roll out of Community Health Centers in the USA. Their focus, however, is primarily on health outcomes among the elderly.

Increasing maternal access to medical professionals is a contemporary issue in developing nations and even in some wealthy countries. Most rich countries have been through phases where increased access to trained personnel has helped reducing maternal mortality, and a number of poorer countries have either gone through this phase recently or are facing it today. To gain a good understanding of this process, it is fruitful to draw both on contemporary and historical data. In this paper, we do the latter, relying on Norwegian data from the period of the extensive roll-out of maternal care.

\section{Historical background}

\subsection{Doctors and midwives}

Until the early 19th century, most doctors located outside of the big cities of Norway had no academic training and were mostly surgeons. In 1836, the roles of medical doctors and surgeons were merged and a system of district doctors ('distriktsleger') was introduced (Sandvik 2000). These doctors were responsible for quality control of vaccinators, midwives, and pharmacies. Initially, each regional doctor was responsible for a vast district, but over time districts were divided up. The Health act ('Sunnhetsloven') of 1860 introduces permanent medical commissions in all cities and municipalities, headed by the district doctor (Schiøtz 2003). Among the roles of this commission was the supervision of work on increasing hygiene in the municipality. Also, from the late 19th century onward, a number of new medical discoveries helped medical doctors in actually curing a number of diseases.

Norway has had midwives since the 16th century, two centuries after the profession first occurred in Germany. ${ }^{1}$ Birth helpers without professional training, 'nærkoner', had however been helping mothers for ages. By the introduction of the new Church ritual in 1685, there should be a midwife in every church district. At the time, one of the key reasons for having midwives was to give emergency baptism to

\footnotetext{
1 See Farstad (2016) and Kjærheim (1987) for more in-depth discussions of the history of midwifery in Norway.
} 
dying babies. About a century later, a midwife school opened in Copenhagen, and in total 65 women were trained before Norwegian independence in 1814 .

In 1818, the first Norwegian midwife school, 'Fødselstiftelsen,' opened in Christiania (today Oslo). Initially, midwives to be were trained for 9 months, in 1830 this was extended to a full year. A second midwife school opened in Bergen in 1861, mostly training midwifes from the western and northern parts of the country. Midwife students were told how to rotate a fetus in case of complicated births. Unlike in Sweden, however, they were not trained in or allowed to use medical instruments such as obstetric forceps before 1902-only medical doctors were allowed to use tools. ${ }^{2}$ From the mid-1880s, midwife students were introduced to antiseptics, which had a major impact on the health of both mothers and babies. An important secondary role of midwives throughout the 18th century was as vaccinators, particularly administering smallpox vaccines in rural areas.

Starting with the midwife law of 1810 , midwives were paid jointly by the region ('amt'), the district, and by the users. To assure the payment of the midwives, they were given a monopoly on providing birth help services. However, the monopoly was difficult to sustain and was abolished 20 years later. From 1898 onward, the midwives were paid jointly by the central government, the region, and the municipality.

Each medical district would have one or several midwife districts, where the midwife of the district was responsible for all births within her district. If the midwife was ill, the midwife of a neighboring district would take over. This was also the case if the position was not filled, which happened quite frequently both due to the wage costs, which led regional councils to delay hiring midwifes, and due to the low wages making it difficult to get qualified applicants.

\subsection{Infant and maternal mortality}

Infant mortality started to fall systematically in Norway early in the 18th century, and around 1850 the Scandinavian countries were the countries with the lowest recorded infant mortality worldwide, only beaten by New Zealand (Edvinsson et al. 2008). Urban mortality rates were clearly higher, mostly due to more unhealthy conditions and a higher frequency of epidemics. The decline in infant mortality is typically attributed to improved nutrition, an improved epidemic climate with fewer infectious diseases, and the home environment (Andrews et al. 2008). As discussed by Thorvaldsen $(2002,2008)$, the practice of breastfeeding was surprisingly low in most European countries well into the 20th century. Both doctors and midwives were instructed to encourage the practice of breastfeeding, which may have affected mortality rates.

Maternal mortality also declined early in the Scandinavian countries. In a classic study, Högberg et al. (1986) find that most of the decline occurred in the second half of the 19th century in Sweden. The same pattern can be found in Norway (Kjærheim 1987; Loudon 1992). Most other rich countries did not see marked declines in

\footnotetext{
${ }^{2}$ The school in Bergen had a more relaxed attitude to the forceps, teaching its use from the mid-1880s.
} 
maternal mortality until the 1930 s - then partially due to improved medical knowledge such as sulfa drugs (Thomasson and Treber 2008).

While there was a socio-economic gradient in maternal mortality, economic development was not a key driver of reduced maternal mortality according to Loudon (2000). Rather, there seems to be a strong consensus that the main driver of the fall in maternal mortality is due to increased access to health personnel (de Brouwere 2007) and increased quality of services provided (Loudon 2000; Anderson et al. 2020). Högberg et al. (1986) emphasize the role of knowledge about sanitation, which had a massive impact on maternal mortality in hospitals, but also played a role for women giving birth at home. Finally, Loudon (1992) mentions a decline in the virulence of the streptococcus bacteria as a third source of the decline.

\section{Data and descriptive statistics}

\subsection{Sources}

Most of the data we use in this paper is drawn from annual medical reports where local physicians reported on the medical conditions in their locality. ${ }^{3}$ From 1879 , the reports contain standardized tables with the number of medical personnel (medical doctors, midwives, and assistant vaccinators as well as dentists for the last years) per municipality. The reports also contain tables on the number of births, stillbirths, deaths, infant (first year, first day) and child mortality, maternal mortality, accidental deaths and suicides. This is reported at the medical district level, but these data are only available until 1921-maternal mortality only until 1920, defining the end of our period of study.

We have digitized the data from the printed tables. For each municipality, we have the number of doctors, dentists, midwives and vaccinators. This is also aggregated to the medical district and county level and combined with the mortality data. Moreover, each report lists the number of inhabitants as of the latest decennial census and the land area of the municipalities. We define all rates as events per children born, as total population numbers at the municipality level is only available for census years (1891, 1900, 1910 and 1920).

There are substantial changes in the structure of municipalities and medical districts in Norway in the period studied. We base our municipal structure on lists of municipalities by year made available by the Norwegian Centre for Research Data (NSD). In some cases, the year of a municipality merger or split is not the same in the medical reports and the NSD data; in those cases, we follow the medical reports. The number of medical districts also increase substantially, so that the average number of municipalities in each medical district (and the average medical district population) decreases over time. To ensure that our analysis is not affected by these changes in regional aggregation, we conduct our analysis at a harmonized medical

\footnotetext{
${ }^{3}$ Full details of the reports are given in "Appendix 6".
} 
Table 1 Descriptive statistics

\begin{tabular}{|c|c|c|c|c|c|c|}
\hline & \multirow{2}{*}{\multicolumn{2}{|c|}{$\frac{\text { All }}{(1)}$}} & \multirow{2}{*}{\multicolumn{2}{|c|}{$\frac{\text { Rural }}{(2)}$}} & \multirow{2}{*}{\multicolumn{2}{|c|}{$\frac{\text { Urban }}{(3)}$}} \\
\hline & & & & & & \\
\hline & Mean & SD & Mean & $\mathrm{SD}$ & Mean & $\mathrm{SD}$ \\
\hline \multicolumn{7}{|l|}{ Mortality } \\
\hline Maternal mortality per 100,000 born & 430.61 & 233.32 & 464.30 & 241.06 & 384.52 & 226.42 \\
\hline Day 1 mortality per 1000 born & 7.21 & 1.62 & 7.01 & 1.72 & 7.74 & 1.22 \\
\hline Infant mortality per 1000 born & 75.87 & 22.13 & 74.16 & 22.05 & 80.04 & 22.43 \\
\hline \multicolumn{7}{|l|}{ Health personnel } \\
\hline Midwives & 9.42 & 8.21 & 6.31 & 4.25 & 15.04 & 10.83 \\
\hline Doctors & 5.89 & 6.79 & 3.25 & 3.95 & 10.42 & 7.64 \\
\hline Vaccinators & 6.47 & 5.50 & 5.31 & 3.36 & 8.68 & 7.90 \\
\hline$N$ & 106 & & 66 & & 34 & \\
\hline
\end{tabular}

Descriptive statistics, average of all years 1887-1920. Standard deviations in parentheses. Column 1 is for all areas, column 2 is only rural areas and column 3 is only urban areas

district level, where the medical districts in any given period are aggregated up to form a unit that does not change over time.

In total, there are between 583 and 704 municipalities and between 156 and 384 medical districts (depending on year) across Norway's 20 counties. These can be aggregated to form 106 time-invariant units. All municipalities are defined as either rural or urban by the definitions used in the reports at the time. Urban municipalities controlled a larger set of policies, had an industrial structure that differed from rural municipalities and were densely built up, but could still be relatively small. When we aggregate municipalities to time-invariant units, we define a region as urban if it includes an urban municipality (e.g., a city or town). We show descriptive statistics for the whole sample and divided by rural and urban areas in Table 1.

\subsection{Mortality}

We now consider the data on mortality for the period 1887-1920. In Panel (a) of Fig. 1, we present the average maternal mortality per 100,000 children born. It is notable that the levels are very high in the beginning of the period, with a mean mortality rate of 736 deaths per 100,000 births across all medical districts. In 1920, this has decreased to a mean of 300 , a remarkable decline. ${ }^{4}$

The infant mortality rate (IMR) is the number of infants dying before reaching one year of age, per 1000 live births in a given year. In Panel (b) of Fig. 1, we present the infant mortality rate in Norway during our period. Panel (c) of Fig. 1 shows the mortality rate during the first day after birth. Infant mortality also shows a clear

\footnotetext{
4 The rates are actually higher at the beginning of the period than the rates in today's Sub-Saharan Africa (which have a maternal mortality rate of 480 deaths per 100,000 live births).
} 
Fig. 1 Mortality over time. Notes: The figure shows yearly averages and means of maternal, infant (first life year), and first day of life mortality across harmonized medical districts. The bands show 25 and 75 percentiles of the observed distribution. No observed maternal mortality is observed in some municipalities

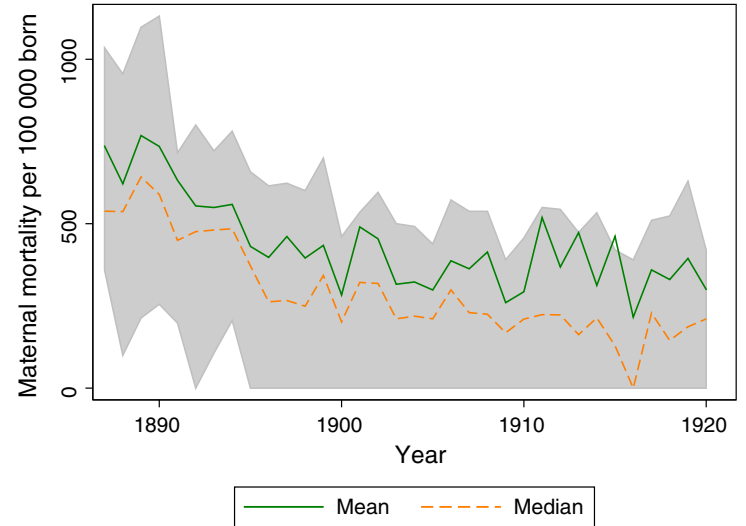

(a) Maternal mortality

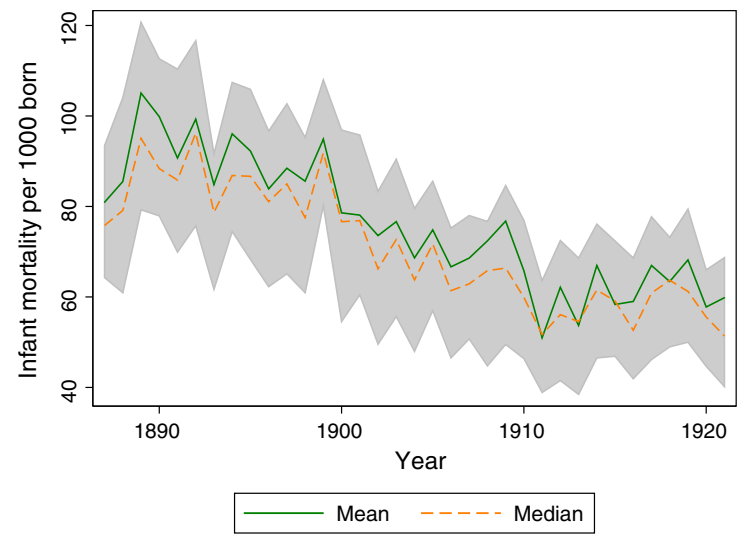

(b) Infant mortality

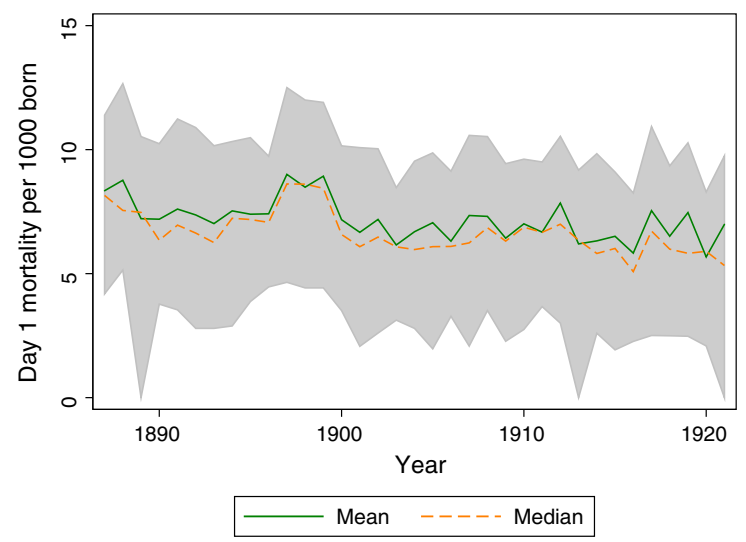

(c) Day 1 mortality 


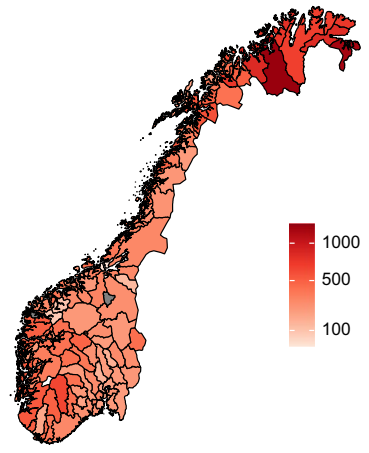

(a) Maternal mortality

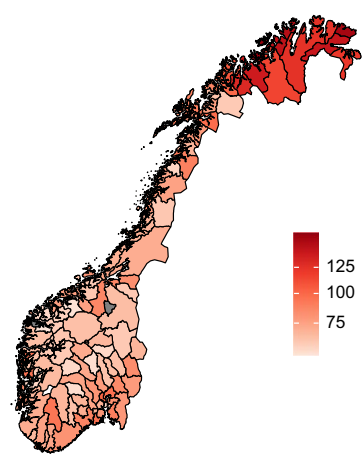

(b) Infant mortality

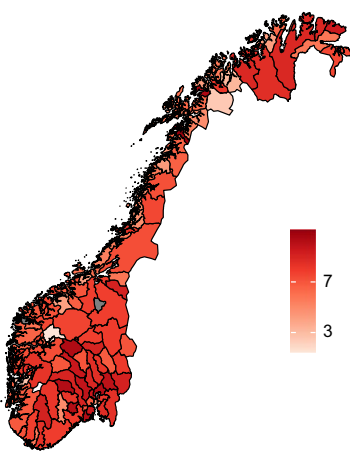

(c) Day 1 mortality

Fig. 2 Mortality around 1900. Notes: The figure shows average maternal, infant (first life year), and neonatal (first day of life) mortality per 1000 and 100,000 (maternal) births in the period 1895 to 1905 . Data are aggregated by harmonized medical district

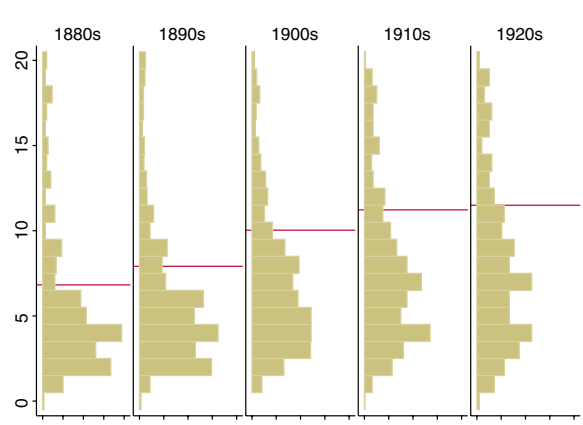

(a) Midwives

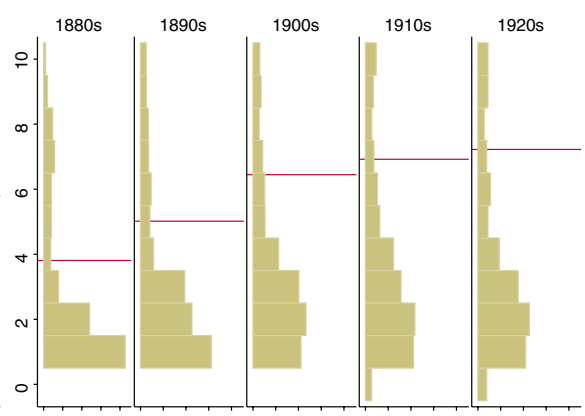

(b) Doctors

Fig. 3 Distribution of midwives and doctors over time. Notes: The figures show the change in the distribution of health personnel per harmonized medical district across decades. The red line shows the decade average. Histograms are capped at 20 midwives and 10 doctors

downward trend over the period, declining from an average of 80.94 to 59.83 over the period at hand. The change in day one mortality is less pronounced, decreasing from 8.34 to 6.99 , also exhibiting a high variance over time. Figure 2 shows the distribution of mortality per 100,000 residents by municipality in 1900 . Mortality is higher in most of the Northern areas as well as the central eastern areas.

These figures correspond well to the review of the development of mortality in Norway over time given by Backer (1961, p. 44). Backer emphasizes a steady fall in mortality from the 1880 s onward. Important drivers of this decrease were improvements in infection control and a substantial fall in deaths from tuberculosis. In addition, an improvement in hygiene and public health services is emphasized as explanatory factors. Child mortality also fell throughout the period, but mortality for the youngest children was relatively stable in the later decades of the nineteenth century, only starting to fall after 1900 . 


\subsection{Coverage of health personnel}

Panel (a) of Fig. 3 shows the evolution of the number of midwives per harmonized medical district over time. There are in total 699 midwives in 1887, increasing steadily to 1296 in 1920 . The increase is mostly due to the upper tail of the distribution becoming thicker-although some municipalities maintain low numbers of midwifes, the number of municipalities with numerous midwives increase. As can be seen from the maps in Fig. 4, there is also substantial spatial variation. The evolution of the number of medical doctors follows a similar pattern (Panel (b) of Fig. 3, but the numbers are smaller and doctors are to a larger extent concentrated around the large cities (Panels (b) and (d) of Fig. 4.

\section{Empirical strategy and main results}

\subsection{Empirical strategy}

There are many reasons why districts may have different shares of health personnel and different rates of mortality. When assessing the effects of health personnel on mortality, we are particularly worried about other factors that are not controlled for but that may be linked to both the dependent and the independent variable of interest. For instance, some areas may have a culture that is more focused on health, which is likely to be correlated with more spending on health and lower mortality. To control for such factors, we estimate the relationship between mortality and health personnel using multivariate OLS regression with the specification:

$$
\text { Mortality }_{d t}=\alpha+\beta \text { Personnel }_{d t}+\gamma_{t}+\theta_{d}+\delta_{(d t)}+\epsilon_{d t},
$$

where $d$ is harmonized medical district and $t$ is year. The district fixed effects capture stable geographical heterogeneity, the year fixed effects capture aggregate shocks, and the district specific time trends capture differential development across space, e.g., in income growth. We use log transformations on both the dependent and the main independent variables. The measured effect can then be read directly as an elasticity and the specification becomes less sensitive to outliers. The standard errors are clustered at the district level.

The year and district fixed effects lead to a typical "difference-in-differences" (DiD) setup, where the underlying assumption is that all districts would follow the same mortality path (albeit from different starting points) in the absence of health personnel changes. In the DiD setup, we control for the fact that districts with more health personnel are likely to differ from districts with less. In particular, we are comparing the change in districts with increased personnel to the change at the same point in time for districts not increasing their personnel at this specific time. The district and year fixed effects imply that we are controlling for all differences that are stable across districts over time. This involves many strong predictors of mortality such as the time invariant components of culture and climate. 


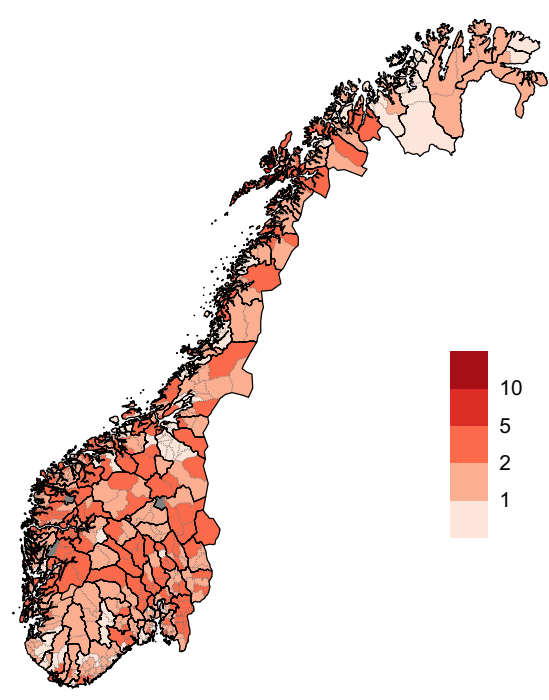

(a) Midwives 1890

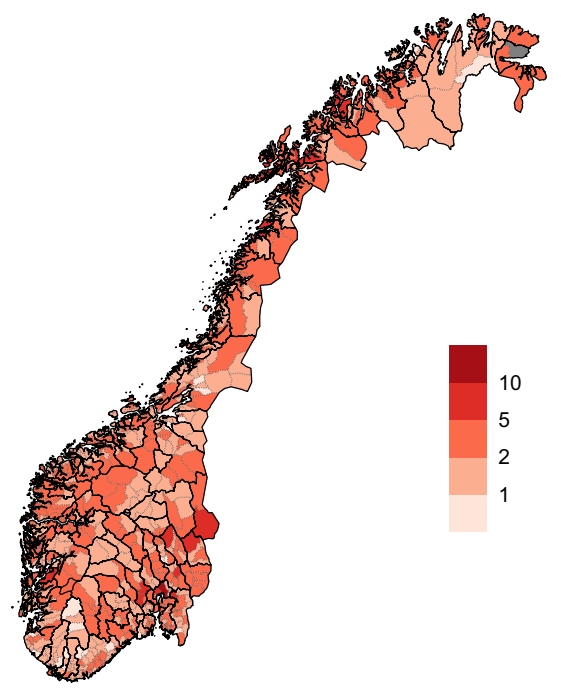

(c) Midwives 1920

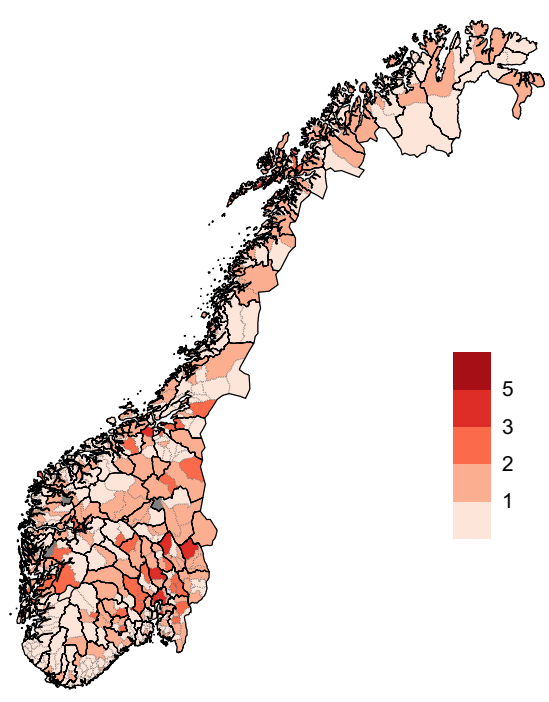

(b) Doctors 1890

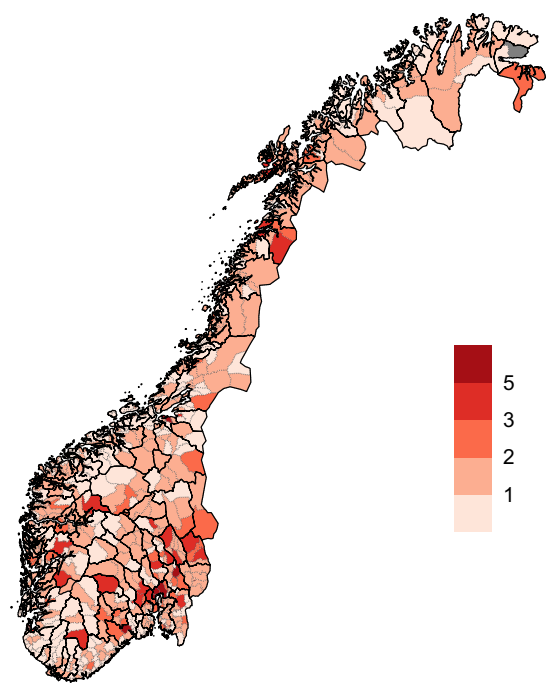

(d) Doctors 1920

Fig. 4 Geographic distribution of medical personnel. Data are shown by municipality, while boundaries of harmonized medical districts are shown as black lines

The main assumption in this type of analysis is that all districts would follow the same trend in the absence of personnel changes. One potential confounding factor is that there may be different trends in the districts and we therefore allow for a more flexible specification using district-specific time trends. This relaxes the assumption of similar trends further, as there is a linear time trend for each district and 
Table 2 Midwives and maternal mortality

\begin{tabular}{lllllll}
\hline & $(1)$ & $(2)$ & $(3)$ & $(4)$ & $(5)$ & $(6)$ \\
& Logged & Logged & Logged & Logged & Levels & Levels \\
& All & All & Rural & Urban & All & Rural \\
\hline Logged nr of midwives & $-0.79 *$ & $-1.34 * * *$ & $-1.32^{* * *}$ & 0.29 & $-225.3^{*}$ & $-343.4^{* * *}$ \\
& $(0.41)$ & $(0.49)$ & $(0.49)$ & $(0.67)$ & $(119.7)$ & $(144.8)$ \\
Logged nr of midwives * Urban & & $1.86^{* *}$ & & & & \\
Transformation & & $(0.83)$ & & & & Levels \\
Sample & Logged & Logged & Logged & Logged & Levels & Rural \\
Mean dep. var & All & All & Rural & Urban & All & 455.17 \\
No. of observations & 4.12 & 4.12 & 3.84 & 4.68 & 430.61 & 4514 \\
$R^{2}$ & 3603 & 3603 & 2414 & 1189 & 3603 & 2414 \\
\hline
\end{tabular}

The dependent variable is maternal mortality per 100,000 born children. In columns $1-4$, we take the $\log$ of $1+$ this number and in columns 5 and 6 we instead have the number in levels as the dependent variable. All regressions control for year and district fixed effects as well as district specific time trends. Robust standard errors clustered at the medical district level in parentheses

we estimate whether the change in personnel leads to deviations from that trend. This setup allows for differences in time-varying development between districts even without changes in personnel, such as in economic development.

\subsection{Main results}

In Table 2, we present results where we regress maternal mortality rates on the number of midwives with year and district fixed effects, as well as district specific linear time trends. ${ }^{5}$ We see in column 1 that an increase in the number of midwives decrease maternal mortality, but the effect is only statistically significant at the $10 \%$ level. These overall results mask a substantial differences between rural and urban areas, however. In column 2, we interact the logged number of midwives with an indicator variable for urban areas and we see that the effect is driven by the rural areas and that there is a statistically significant difference between urban and rural areas. In columns 3 and 4, we show the results separately by rural and urban areas and we see that there is only an effect in rural areas.

We notice a strong relationship between midwives and maternal mortality in rural areas. A $10 \%$ increase in the number of midwives would lead to a $13.2 \%$ reduction in maternal mortality. Hence for the average medical district, the addition of one midwife would reduce maternal deaths by 92 per 100,000 children born. ${ }^{6}$ As stated

\footnotetext{
5 Specifically, we use the transformation $x \mapsto \log (1+x)$ for mortality rates and the number of midwives to maintain zeros. We show below that results are robust to this choice of specification.

6 This calculation is based on going from 5.58 to 6.58 midwives ( $17.9 \%$ increase) times $\beta=1.32$ times 3.91 maternal deaths.
} 
Table 3 Midwives and infant mortality

\begin{tabular}{lllllll}
\hline & $(1)$ & $(2)$ & $(3)$ & $(4)$ & $(5)$ & $(6)$ \\
& Logged & Logged & Logged & Logged & Levels & Levels \\
& All & All & Rural & Urban & All & Rural \\
\hline Logged nr of midwives & 0.014 & 0.026 & 0.022 & 0.0078 & -2.97 & -4.89 \\
& $(0.066)$ & $(0.078)$ & $(0.079)$ & $(0.13)$ & $(4.35)$ & $(5.53)$ \\
Logged nr of midwives * Urban & & -0.041 & & & & \\
Transformation & & $(0.14)$ & & & & \\
Sample & Logged & Logged & Logged & Logged & Levels & Levels \\
Mean dep. var & All & All & Rural & Urban & All & Rural \\
No. of observations & 4.23 & 4.23 & 4.20 & 4.31 & 75.87 & 73.42 \\
$R^{2}$ & 3603 & 3603 & 2414 & 1189 & 3603 & 2414 \\
\hline
\end{tabular}

The dependent variable is infant mortality per 1000 born children. In columns $1-4$, we take the log of 1 + this number and in columns 5 and 6 we instead have the number in levels as the dependent variable. All regressions control for year and district fixed effects as well as district specific time trends. Robust standard errors clustered at the medical district level in parentheses

Table 4 Midwives and neonatal mortality

\begin{tabular}{lllllll}
\hline & $(1)$ & $(2)$ & $(3)$ & $(4)$ & $(5)$ & $(6)$ \\
& Logged & Logged & Logged & Logged & Levels & Levels \\
& All & All & Rural & Urban & All & Rural \\
\hline Logged nr of midwives & -0.22 & $-0.28^{*}$ & -0.27 & -0.0078 & $-1.67^{*}$ & $-2.35^{* *}$ \\
& $(0.13)$ & $(0.17)$ & $(0.17)$ & $(0.20)$ & $(0.90)$ & $(1.09)$ \\
Logged nr of midwives * Urban & & 0.23 & & & & \\
Transformation & & $(0.25)$ & & & & Levels \\
Sample & Logged & Logged & Logged & Logged & All & Rural \\
Mean dep. var & All & All & Rural & Urban & All \\
No. of observations & 1.76 & 1.76 & 1.64 & 1.99 & 7.21 & 6.95 \\
$R^{2}$ & 3603 & 3603 & 2414 & 1189 & 3603 & 2414 \\
\hline
\end{tabular}

The dependent variable is neonatal mortality per 1000 born children. In columns $1-4$, we take the log of $1+$ this number and in columns 5 and 6 we instead have the number in levels as the dependent variable. All regressions control for year and district fixed effects as well as district specific time trends. Robust standard errors clustered at the medical district level in parentheses

above, rural medical districts covered much larger geographical areas, and initial coverage of health personnel was lower than in cities. There are also other differences between cities and rural areas that are potentially important, such as the generally lower mortality (Backer 1961, chap. 10) and lower income inequality (Modalsli 2018) in rural areas. In columns 5 and 6, we show that the conclusions are similar if we estimate the effects on mortality in levels instead of in logs. 
Table 5 Midwives and other medical personnel. Rural areas

\begin{tabular}{llll}
\hline & $(1)$ & $(2)$ & $(3)$ \\
& Doctors & Dentists & Vaccinators \\
\hline Logged nr of midwives & 0.029 & 0.065 & $0.30 * * *$ \\
& $(0.067)$ & $(0.054)$ & $(0.064)$ \\
Mean dep. var & 1.27 & 0.17 & 1.75 \\
No. of observations & 2414 & 2414 & 2414 \\
No. of districts & 71 & 71 & 71 \\
$R^{2}$ & 0.52 & 0.70 & 0.64
\end{tabular}

The dependent variables are logged. All regressions control for year and district fixed effects as well as district specific time trends. Robust standard errors clustered at the medical district level in parentheses

Table 6 Medical personnel and mortality. Rural areas

\begin{tabular}{llll}
\hline & $(1)$ & $(2)$ & $(3)$ \\
& Maternal mortality & Day 1 mortality & \begin{tabular}{l} 
Infant mortality \\
\hline Logged nr of midwives
\end{tabular} \\
& $-1.32^{* *}$ & -0.24 & 0.016 \\
Logged nr of doctors & $(0.54)$ & $(0.19)$ & $(0.089)$ \\
& 0.38 & -0.048 & -0.036 \\
Logged nr of vaccinators & $(0.37)$ & $(0.17)$ & $(0.061)$ \\
& -0.029 & -0.084 & 0.024 \\
Mean dep. var & $(0.69)$ & $(0.24)$ & $(0.095)$ \\
No. of observations & 3.84 & 1.64 & 4.20 \\
$R^{2}$ & 2414 & 2414 & 2414 \\
\hline
\end{tabular}

The dependent variables are logged ratios. All regressions control for year and district fixed effects as well as district specific time trends. Robust standard errors clustered at the medical district level in parentheses

In Tables 3 and 4, we see that the effects are in the same direction for infant and neonatal mortality, but that the effects are smaller and often not statistically significant. One explanation for this may be that our sample is too small to detect effects of low magnitude. We show in Appendix Sect. 1 that the main results on maternal mortality are robust to using the number of midwives per children born instead of taking logs. The results for neonatal mortality are always negative whereas the results for infant mortality are less robust.

In what follows, we focus the analysis on the rural sample. ${ }^{7}$ We note that there is a positive relationship between the number of midwives and the number of

\footnotetext{
${ }^{7}$ In Appendix Sect. 5, we present the results for Tables 5, 6, 7, 8, 9, 10, 11, 12 and 14 for the urban sample as well. We prefer to present the results separately rather than having interaction terms as this is easier to interpret.
} 
Table 7 Health personnel and placebo causes of death. Rural areas

\begin{tabular}{lllllllll}
\hline & $(1)$ & $(2)$ & $(3)$ & $(4)$ & $(5)$ & $(6)$ & $(7)$ & $(8)$ \\
& Murder & Murder & Accident & Accident & Suicide & Suicide & Other & Other \\
\hline Logged nr of midwives & 0.031 & 0.031 & 0.078 & 0.12 & 0.0068 & -0.040 & 6.63 & 2.13 \\
& $(0.055)$ & $(0.061)$ & $(0.17)$ & $(0.17)$ & $(0.15)$ & $(0.16)$ & $(4.03)$ & $(3.78)$ \\
Logged nr of doctors & & 0.0096 & & 0.067 & & -0.060 & -1.43 \\
Logged nr of vaccinators & & $(0.045)$ & & $(0.11)$ & & $(0.12)$ & $(2.36)$ \\
& & 0.00063 & & -0.15 & & 0.16 & & $15.2 * *$ \\
Mean dep. var & & $(0.062)$ & & $(0.18)$ & & $(0.18)$ & $(6.08)$ \\
No. of observations & 2414 & 2414 & 2414 & 2414 & 2414 & 2414 & 2414 & 2414 \\
$R^{2}$ & 0.09 & 0.09 & 0.32 & 0.32 & 0.20 & 0.20 & 0.97 & 0.97 \\
\hline
\end{tabular}

The dependent variables are logged ratios. All regressions control for year and district fixed effects as well as district specific time trends. Robust standard errors clustered at the medical district level in parentheses

Table 8 Midwives and mortality, dynamic effects. Rural areas

\begin{tabular}{llll}
\hline & $(1)$ & $(2)$ & $(3)$ \\
& Maternal mortality & Day 1 mortality & Infant mortality \\
\hline Logged nr of midwives & -0.39 & -0.32 & 0.080 \\
Lagged midwives & $(0.73)$ & $(0.26)$ & $(0.20)$ \\
& -1.14 & -0.24 & -0.095 \\
2 lags midwives & $(0.84)$ & $(0.28)$ & $(0.19)$ \\
& -0.11 & 0.25 & 0.15 \\
Forward midwives & $(0.80)$ & $(0.28)$ & $(0.18)$ \\
& -0.38 & 0.058 & -0.026 \\
2 leads midwives & $(0.82)$ & $(0.25)$ & $(0.20)$ \\
& -0.52 & -0.066 & -0.12 \\
Mean dep. var & $(0.77)$ & $(0.36)$ & $(0.11)$ \\
No. of observations & 3.77 & 1.63 & 4.20 \\
$R^{2}$ & 2130 & 2130 & 2130 \\
\hline
\end{tabular}

The dependent variables are logged ratios. All regressions control for year and district fixed effects as well as district specific time trends. Robust standard errors clustered at the medical district level in parentheses

vaccinators (see Table 5). Controlling for the other types of health personnel may therefore be important and the results of such an estimation is presented in Table 6. We observe that the coefficient on the number of doctors and vaccinators are lower in magnitude, sometimes even with the opposite sign, and never statistically significant. The results for midwives are very similar to the ones in the baseline specification. In Appendix Tables 18 and 19, we show results for the other categories of 
Table 9 Poverty shocks and provision of medical personnel. Rural areas

\begin{tabular}{llll}
\hline & $(1)$ & $(2)$ & $(3)$ \\
& Midwives & Doctors & Vaccinators \\
\hline Share poor people in the district & -0.0014 & 0.035 & -0.045 \\
& $(0.043)$ & $(0.038)$ & $(0.043)$ \\
Mean dep. var & 1.86 & 1.27 & 1.75 \\
No. of observations & 2414 & 2414 & 2414 \\
$R^{2}$ & 0.95 & 0.92 & 0.94 \\
\hline
\end{tabular}

The dependent variables are logged. All regressions control for year and district fixed effects as well as district specific time trends. Robust standard errors clustered at the medical district level in parentheses

Table 10 Mortality and poverty shocks. Rural areas

\begin{tabular}{llll}
\hline & $(1)$ & $(2)$ & $(3)$ \\
& Maternal mortality & Day 1 mortality & \begin{tabular}{l} 
Infant mortality \\
\hline Share poor people in the district
\end{tabular} \\
& -0.077 & 0.13 & -0.025 \\
Mean dep. var & $(0.32)$ & $(0.10)$ & $(0.034)$ \\
No. of observations & 3.84 & 1.64 & 4.20 \\
$R^{2}$ & 2414 & 2414 & 2414 \\
& 0.17 & 0.17 & 0.39
\end{tabular}

The dependent variables are logged ratios. All regressions control for year and district fixed effects as well as district specific time trends. Robust standard errors clustered at the medical district level in parentheses

Table 11 Service provision and poverty levels. No controls for district fixed effects. Rural areas

\begin{tabular}{llll}
\hline & $(1)$ & $(2)$ & $(3)$ \\
& Midwives & Doctors & Vaccinators \\
\hline Share poor people in the district & -0.054 & 0.029 & -0.067 \\
& $(0.052)$ & $(0.050)$ & $(0.047)$ \\
Mean dep. var & 1.86 & 1.27 & 1.75 \\
No. of observations & 2414 & 2414 & 2414 \\
$R^{2}$ & 0.08 & 0.05 & 0.04 \\
\hline
\end{tabular}

The dependent variables are logged. All regressions control for year fixed effects. Robust standard errors clustered at the medical district level in parentheses

health personnel separately and we note that they are not statistically significantly related to mortality in such specifications.

We also present results for three different time periods (1887-1897, 1898-1907, and 1908-1920) in Appendix Tables 20, 21, 22, 23, 24 and 25. The coefficients for midwives is almost always negative for all three types of mortality. The coefficient for doctors on infant mortality is always negative, and statistically significantly so in the period 1898-1907. When pooling all the data together and interacting the 
Table 12 Mortality and poverty levels. No controls for district fixed effects. Rural areas

\begin{tabular}{llll}
\hline & $(1)$ & $(2)$ & $(3)$ \\
& Maternal mortality & Day 1 mortality & \begin{tabular}{l} 
Infant mortality \\
\hline Share poor people in the district
\end{tabular} \\
& 0.13 & -0.051 & $0.060^{* *}$ \\
Mean dep. var & $(0.13)$ & $(0.046)$ & $(0.027)$ \\
No. of observations & 3.84 & 1.64 & 4.20 \\
$R^{2}$ & 2414 & 2414 & 2414 \\
\hline
\end{tabular}

The dependent variables are logged ratios. All regressions control for year fixed effects. Robust standard errors clustered at the medical district level in parentheses

time periods with midwives, however, we note that no differences are statistically significant.

\subsection{Placebos and timing}

In this section, we assess the main threats to the identification strategy by testing if there is any "placebo" effect on outcomes that should not be affected and by testing whether there is an "effect" before the midwives appear. To assess a possible mechanism for why midwives have an effect, as opposed to, e.g., doctors, we also investigate whether the services seem to be allocated in different ways with respect to poverty.

\subsubsection{Placebos}

In our dataset, we have information about deaths that are likely to be unrelated to (or at least less related to) health personnel. In particular, we have data on murders, accidents, and suicides. If there is some other factor shifting at the same time as the change in medical personnel, and this factor affects mortality irrespective of the health system, we should expect to find differences also on these variables. Table 7 shows that these deaths are unrelated to the number of health personnel, and hence that there are no such "effects." In the last two columns, we also include a measure of other deaths, i.e., deaths in the district that are not maternal, neonatal, or infant deaths. The number of midwives is positively associated with these other causes of deaths, indicating that if there is a bias in our baseline estimates it is toward zero.

\subsubsection{Timing of the effects}

As the data at hand is annual data, we cannot observe when during the year a change in the number of health personnel occurs. It is plausible to believe that some of the observed births occurred before the change in health personnel, and some after. For infant mortality, which occurs sometime between the 1st and the 365th day of a child's life, the timings of the arrival of the health personnel may matter for observed effects. For day one mortality, it is least problematic to measure the 
instantaneous effect and for maternal mortality it is in between. To overcome these challenges, we study the effect of lagged health personnel.

Investigating the timing of effects also gives us the opportunity to investigate another threat to the identification strategy: sluggish and gradual changes. Suppose for instance that there is some slowly evolving factor, say "modernity," that affects both healthcare spending and health outcomes. This could lead to a spuriously significant lead coefficient. In Table 8, we show the results when including two lags and two leads. We find it comforting that the leads are not statistically significant. We also see that the one year lag coefficient seems to be larger that the contemporaneous coefficient for maternal mortality. When testing whether the lag plus the contemporaneous coefficient is different from zero, we find indications that they are for maternal mortality $(p=0.07)$ and for day one mortality $(p=0.03)$.

\section{The role of poverty and emigration}

A possible threat to our results could be that health personnel and health outcomes shift with economic shocks. Richer areas having better health care or different trends in different areas would be controlled for by the district fixed effects and district specific trends and are hence not challenges to identification. Still, a shock to poverty could reduce both health spending and affect mortality differentially at exactly the same time. For this to be a threat to our identification strategy, we should see that services correlate with poverty shocks, that poverty shocks affect mortality, and that the effect of services disappears when we control for the time varying level of poverty. We investigate the three aspects in turn.

We base our measure of poverty on the number of heads-of-households receiving poverty relief. Poverty relief was awarded by municipalities and is reported annually (at the municipality level) in reports published by Statistics Norway. ${ }^{8}$ The "poor share" is then the number of poor divided by total population in the municipality. As total population is only available in Census years (1891, 1900, 1910 and 1920), we interpolate the data between the years. In Appendix Section 4, we present the results without interpolation. It should also be kept in mind that the exact implementation of supplying poverty support was partially a municipal decision. Hence, it may be that more affluent or generous areas report higher level of poverty because the rules where more inclusive.

The share of poor people in the rural districts ranges from 0.5 to $8 \%$. We measure the effect of one standard deviation change in poverty on our outcomes (one standard deviation conveniently corresponding to 1 percentage point in our data as well). In Table 9, we present the results. Health service provision is weakly and often positively correlated with poverty shocks, and the effects are not statistically significant. In Table 10, we see that maternal mortality and infant mortality is negatively correlated with poverty shocks, but neonatal mortality is positively so. Neither these results are statistically significant.

\footnotetext{
${ }^{8}$ We use transcriptions of this data provided by the NSD Municipal Database (Norwegian Centre for Research Data 2017).
} 
Table 13 Maternal mortality with time varying controls

\begin{tabular}{|c|c|c|c|c|c|c|}
\hline & (1) & (2) & (3) & (4) & (5) & (6) \\
\hline & All & All & Rural & Urban & All & Rural \\
\hline Logged $\mathrm{nr}$ of midwives & $\begin{array}{l}-0.75^{*} \\
(0.43)\end{array}$ & $\begin{array}{l}-1.30^{* *} \\
(0.52)\end{array}$ & $\begin{array}{l}-1.30 * * \\
(0.52)\end{array}$ & $\begin{array}{l}0.16 \\
(0.70)\end{array}$ & $\begin{array}{l}-203.3^{*} \\
(120.2)\end{array}$ & $\begin{array}{l}-318.2^{\text {** }} \\
(145.4)\end{array}$ \\
\hline Logged $\mathrm{nr}$ of midwives * Urban & & $\begin{array}{l}1.81 * * \\
(0.83)\end{array}$ & & & & \\
\hline Logged population & $\begin{array}{l}-0.64 \\
(1.14)\end{array}$ & $\begin{array}{l}-0.41 \\
(1.17)\end{array}$ & $\begin{array}{l}-0.23 \\
(1.28)\end{array}$ & $\begin{array}{l}0.58 \\
(2.58)\end{array}$ & $\begin{array}{l}-358.9^{* * *} \\
(129.3)\end{array}$ & $\begin{array}{l}-267.4^{*} \\
(136.8)\end{array}$ \\
\hline Share poor people & $\begin{array}{l}3.86 \\
(20.0)\end{array}$ & $\begin{array}{l}1.89 \\
(19.5)\end{array}$ & $\begin{array}{l}-7.31 \\
(25.5)\end{array}$ & $\begin{array}{l}31.2 \\
(28.8)\end{array}$ & $\begin{array}{l}1589.0 \\
(4159.3)\end{array}$ & $\begin{array}{l}-1384.7 \\
(5156.0)\end{array}$ \\
\hline Mean dep. var & 4.12 & 4.12 & 3.84 & 4.68 & 430.61 & 455.17 \\
\hline No. of observations & 3603 & 3603 & 2414 & 1189 & 3603 & 2414 \\
\hline$R^{2}$ & 0.19 & 0.19 & 0.18 & 0.23 & 0.27 & 0.27 \\
\hline
\end{tabular}

The dependent variables are logged ratios. All regressions control for year fixed effects. Robust standard errors clustered at the medical district level in parentheses

Hence, poverty shocks do not seem to pose a threat for our identification strategy. Nonetheless, differences in poverty across districts may still be correlated with service provision, and as such they may help us understand the mechanisms behind the effects. We therefore present analyses where we only control for year fixed effects to see the distribution of services. We still cluster the standard errors at the district level to account for the fact that observations are not independent within districts over time.

In Table 11, we see that a standard deviation in the share of poor people is not statistically significantly associated with more or less personnel. In Table 12, we see that poorer districts have statistically significantly higher infant mortality. They do not have statistically significantly higher maternal and neonatal mortality. Finally, we show in Table 13 that all our main results are robust to controlling for both poverty and population. ${ }^{9}$

There was substantial overseas emigration from Norway in the period we study, primarily to North America. Abramitzky et al. (2012) examine the selection of Norwegian migrants in the 1865-1900 period and conclude that in urban areas, individuals in low-income occupations were more likely to emigrate than individuals in high-income occupations. While the results from the Abramitzky et al. study are mixed when it comes to rural areas, and it is not clear how differing emigration rates could influence the relationship between health personnel and mortality, it is still of interest to examine whether the relationships differ between regions of high and low emigration. To investigate this, we use reports of the number of emigrants originating from each municipality, again digitized and made available in the

\footnotetext{
9 In Appendix Section 5, we see that poverty shocks are positively correlated with midwives for urban areas (Table 34), but the results are sensitive to the exact specification used and change sign if district fixed effects are not included (Table 36).
} 


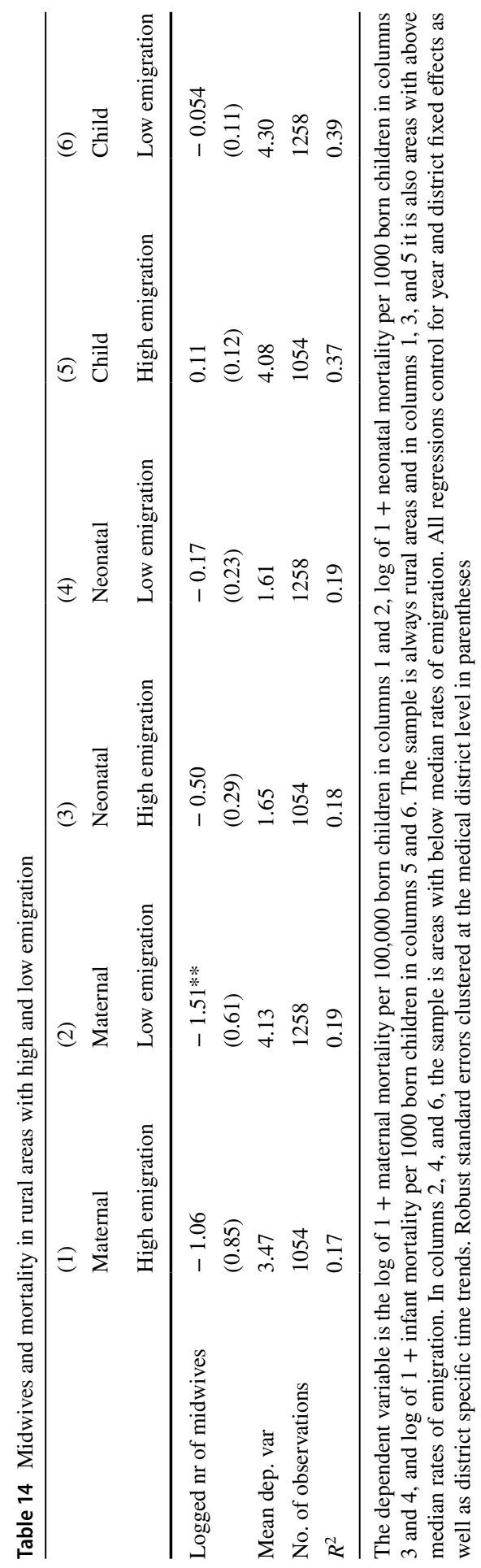


NSD Municipal Database, to calculate average emigration rates by region for the time period we study. In Table 14, we split the rural sample into areas with high and low emigration (defined as the average rate for the 1887-1920 period). We see that the effects of midwives on maternal and neonatal mortality is negative and relatively similar across the two types of areas. The effects on maternal mortality are higher in the areas with low emigration, but the differences across areas is not statistically significantly different. The effects on infant mortality is of different signs but never statistically significant.

\section{Conclusion}

High infant and maternal mortality has been and is still one of the realities in life in most parts of the world. This paper is the first to use high-quality regionally disaggregated data to study how increased access to medical personnel helped reduce mortality in Norway around the turn of the 20th century. We find that increased access to midwives had a strong effect on reducing maternal mortality. There are no signs of medical doctors decreasing mortality in this period. There are indications of effects also on neonatal and infant mortality but these results are not very robust.

Over the period at hand, the number of midwives per (harmonized) medical district increases from 4.53 to 8.03 in rural areas. Taking our elasticity of 1.27 , the increased access to midwives would lead to a $62 \%$ reduction in maternal mortality. This more than explains the observed decline of $59.6 \%$ observed in rural areas. The large estimated reduction in maternal mortality shows that public investment in social programs in the late nineteenth and early twentieth century probably had substantial effects on human welfare. While the present paper cannot directly identify the mechanisms, it is likely that the relatively new knowledge about hygiene and the use of antiseptics played an important role. The large differences in effects between rural and urban areas suggest that many of the benefits were already realized in the cities, but that midwives were an important channel in the countryside.

We have argued that our results cannot be due to general improvements in living standards and technology or the uneven development in different parts of the country. Neither can it be driven by high levels of poverty affecting both mortality rates and the provision of health services. Hence, it seems that the effect of access to midwives explains most of the decline in mortality. Doctors, however, seem to have little or no effect on either maternal or infant mortality during the period at hand.

The main policy conclusion that can be drawn is that for today's poor countries, improving access to maternal care may be key to reducing high mortality rates among mothers and infants. Medical doctors today do of course have a much larger range of tools, particularly effective medication, at their disposal than did the doctors in Norway a century ago. Hence, the conclusion that doctors have no effect on mortality may not be applicable to a contemporary setting.

We estimate the average effects of medical personnel. In future research, it would be interesting to go further into social gradients in the effect. One conjecture is that the lower classes (albeit maybe not the very lowest) were the groups most benefiting from midwifery services. 


\section{Appendix 1: Robustness}

Tables 15, 16, 17 show that the main results on maternal mortality are robust to using the number of midwives per children born instead of taking logs.

Table 15 Midwives per child born and maternal mortality

Table 16 Midwives per child born and infant mortality

Table 17 Midwives per child born and neonatal mortality

\begin{tabular}{lllll}
\hline & $(1)$ & $(2)$ & $(3)$ & $(4)$ \\
& All & All & Rural & Urban \\
\hline Midwives pb & $-32.7^{* * *}$ & $-32.6^{* *}$ & $-30.8^{* *}$ & $-43.2^{*}$ \\
& $(11.7)$ & $(13.7)$ & $(13.7)$ & $(23.2)$ \\
Midwives pb * Urban & & -0.20 & & \\
& & $(28.0)$ & & \\
Mean dep. var & 4.12 & 4.12 & 3.84 & 4.68 \\
No. of observations & 3603 & 3603 & 2414 & 1189 \\
$R^{2}$ & 0.19 & 0.19 & 0.18 & 0.23 \\
\hline
\end{tabular}

All regressions control for year and district fixed effects as well as district specific time trends. Robust standard errors clustered at the medical district level in parentheses

\begin{tabular}{lllll}
\hline & $(1)$ & $(2)$ & $(3)$ & $(4)$ \\
& All & All & Rural & Urban \\
\hline Midwives pb & 3.26 & 2.07 & 1.85 & $8.08^{*}$ \\
& $(2.03)$ & $(2.22)$ & $(2.27)$ & $(4.24)$ \\
Midwives pb * Urban & & 5.29 & & \\
Mean dep. var & & $(4.51)$ & & \\
No. of observations & 3.23 & 4.23 & 4.20 & 4.31 \\
$R^{2}$ & 3603 & 3603 & 2414 & 1189 \\
\hline
\end{tabular}

All regressions control for year and district fixed effects as well as district specific time trends. Robust standard errors clustered at the medical district level in parentheses

\begin{tabular}{lllll}
\hline & $(1)$ & $(2)$ & $(3)$ & $(4)$ \\
& All & All & Rural & Urban \\
\hline Midwives pb & -6.49 & $-8.19^{*}$ & -7.86 & -0.65 \\
& $(4.06)$ & $(4.75)$ & $(4.74)$ & $(6.19)$ \\
Midwives pb * Urban & & 7.58 & & \\
& & $(8.12)$ & & \\
Mean dep. var & 1.76 & 1.76 & 1.64 & 1.99 \\
No. of observations & 3603 & 3603 & 2414 & 1189 \\
$R^{2}$ & 0.19 & 0.19 & 0.17 & 0.23 \\
\hline
\end{tabular}

All regressions control for year and district fixed effects as well as district specific time trends. Robust standard errors clustered at the medical district level in parentheses 


\section{Appendix 2: Other categories of health personnel}

Table 18 Doctors and mortality (logged). Two way fixed effects regressions with district specific time trends

\begin{tabular}{llll}
\hline & $(1)$ & $(2)$ & $(3)$ \\
& Maternal mortality & Day 1 mortality & Infant mortality \\
\hline Logged nr of doctors & 0.36 & -0.052 & -0.036 \\
& $(0.38)$ & $(0.17)$ & $(0.061)$ \\
Mean dep. var & 3.84 & 1.64 & 4.20 \\
No. of observations & 2414 & 2414 & 2414 \\
$R^{2}$ & 0.17 & 0.17 & 0.39 \\
\hline
\end{tabular}

All regressions control for year and district fixed effects as well as district specific time trends. Robust standard errors clustered at the medical district level in parentheses

Table 19 Vaccinators and mortality (logged). Two way fixed effects regressions with district specific time trends

\begin{tabular}{llll}
\hline & $(1)$ & $(2)$ & $(3)$ \\
& Maternal mortality & Day 1 mortality & Infant mortality \\
\hline Logged nr of vaccinators & -0.49 & -0.17 & 0.030 \\
& $(0.65)$ & $(0.21)$ & $(0.085)$ \\
Mean dep. var & 3.84 & 1.64 & 4.20 \\
No. of observations & 2414 & 2414 & 2414 \\
$R^{2}$ & 0.17 & 0.17 & 0.39 \\
\hline
\end{tabular}

All regressions control for year and district fixed effects as well as district specific time trends. Robust standard errors clustered at the medical district level in parentheses

\section{Appendix 3: Different time periods}


Table 20 Midwives and mortality 1887-1897 (logged). Two-way fixed effects regressions with district specific time trends

\begin{tabular}{llll}
\hline & $(1)$ & $(2)$ & $(3)$ \\
& Maternal mortality & Day 1 mortality & Infant mortality \\
\hline Logged nr of midwives & -2.15 & -0.58 & -0.18 \\
& $(1.30)$ & $(0.72)$ & $(0.13)$ \\
Mean dep. var & 4.64 & 1.69 & 4.41 \\
No. of observations & 781 & 781 & 781 \\
$R^{2}$ & 0.30 & 0.28 & 0.52 \\
\hline
\end{tabular}

All regressions control for year and district fixed effects as well as district specific time trends. Robust standard errors clustered at the medical district level in parentheses

Table 21 Midwives and mortality 1887-1897 (logged). Two way fixed effects regressions with district specific time trends, controlling for other types of health personnel

\begin{tabular}{llll}
\hline & $(1)$ & $(2)$ & $(3)$ \\
& Maternal mortality & Day 1 mortality & Infant mortality \\
\hline Logged nr of midwives & $-2.24^{*}$ & -0.50 & -0.16 \\
Logged nr of doctors & $(1.31)$ & $(0.76)$ & $(0.13)$ \\
& -0.062 & -0.0023 & -0.20 \\
Logged nr of vaccinators & $(1.20)$ & $(0.38)$ & $(0.12)$ \\
& 1.02 & -0.92 & -0.10 \\
Mean dep. var & $(1.74)$ & $(0.80)$ & $(0.21)$ \\
No. of observations & 4.64 & 1.69 & 4.41 \\
$R^{2}$ & 781 & 781 & 781 \\
\hline
\end{tabular}

All regressions control for year and district fixed effects as well as district specific time trends. Robust standard errors clustered at the medical district level in parentheses

Table 22 Midwives and mortality 1898-1907 (logged). Two-way fixed effects regressions with district specific time trends

\begin{tabular}{llll}
\hline & $(1)$ & $(2)$ & $(3)$ \\
& Maternal mortality & Day 1 mortality & Infant mortality \\
\hline Logged nr of midwives & -0.0035 & -0.68 & -0.21 \\
& $(1.48)$ & $(0.56)$ & $(0.18)$ \\
Mean dep. var & 3.63 & 1.67 & 4.22 \\
No. of observations & 710 & 710 & 710 \\
$R^{2}$ & 0.27 & 0.33 & 0.56 \\
\hline
\end{tabular}

All regressions control for year and district fixed effects as well as district specific time trends. Robust standard errors clustered at the medical district level in parentheses 
Table 23 Midwives and mortality 1898-1907 (logged). Two-way fixed effects regressions with district specific time trends, controlling for other types of health personnel

\begin{tabular}{llll}
\hline & $(1)$ & $(2)$ & $(3)$ \\
& Maternal mortality & Day 1 mortality & Infant mortality \\
\hline Logged nr of midwives & -0.045 & -0.67 & -0.22 \\
Logged nr of doctors & $(1.49)$ & $(0.56)$ & $(0.18)$ \\
& -0.25 & 0.23 & $-0.27^{* *}$ \\
Logged nr of vaccinators & $(1.28)$ & $(0.38)$ & $(0.12)$ \\
& 1.75 & 0.27 & 0.19 \\
Mean dep. var & $(1.74)$ & $(0.64)$ & $(0.16)$ \\
No. of observations & 3.63 & 1.67 & 4.22 \\
$R^{2}$ & 710 & 710 & 710 \\
\hline
\end{tabular}

All regressions control for year and district fixed effects as well as district specific time trends. Robust standard errors clustered at the medical district level in parentheses

Table 24 Midwives and mortality 1908-1920 (logged). Two-way fixed effects regressions with district specific time trends

\begin{tabular}{llll}
\hline & $(1)$ & $(2)$ & $(3)$ \\
& Maternal mortality & Day 1 mortality & Infant mortality \\
\hline Logged nr of midwives & -0.70 & $-0.74^{* *}$ & 0.12 \\
& $(1.05)$ & $(0.37)$ & $(0.25)$ \\
Mean dep. var & 3.33 & 1.58 & 4.00 \\
No. of observations & 923 & 923 & 923 \\
$R^{2}$ & 0.23 & 0.25 & 0.25 \\
\hline
\end{tabular}

All regressions control for year and district fixed effects as well as district specific time trends. Robust standard errors clustered at the medical district level in parentheses 
Table 25 Midwives and mortality 1908-1920 (logged). Two-way fixed effects regressions with district specific time trends, controlling for other types of health personnel

\begin{tabular}{llll}
\hline & $(1)$ & $(2)$ & $(3)$ \\
& Maternal mortality & Day 1 mortality & Infant mortality \\
\hline Logged nr of midwives & -0.35 & -0.67 & 0.085 \\
& $(1.17)$ & $(0.41)$ & $(0.29)$ \\
Logged nr of doctors & -0.095 & 0.23 & -0.066 \\
& $(0.77)$ & $(0.34)$ & $(0.12)$ \\
Logged nr of vaccinators & -0.97 & -0.21 & 0.099 \\
& $(1.29)$ & $(0.45)$ & $(0.25)$ \\
Mean dep. var & 3.33 & 1.58 & 4.00 \\
No. of observations & 923 & 923 & 923 \\
$R^{2}$ & 0.23 & 0.25 & 0.25
\end{tabular}

All regressions control for year and district fixed effects as well as district specific time trends. Robust standard errors clustered at the medical district level in parentheses

\section{Appendix 4: The role of poverty: not-interpolated}

Tables 26, 27, 28, 29 shows the role of poverty using non-interpolated data.

Table 26 Service provision and poverty shocks. Rural areas

\begin{tabular}{llll}
\hline & $(1)$ & $(2)$ & $(3)$ \\
& Midwives & Doctors & Vaccinators \\
\hline Share poor people in the district & 0.045 & -0.00035 & 0.030 \\
& $(0.039)$ & $(0.040)$ & $(0.042)$ \\
Mean dep. var & 1.88 & 1.28 & 1.76 \\
No. of observations & 284 & 284 & 284 \\
$R^{2}$ & 0.92 & 0.87 & 0.88 \\
\hline
\end{tabular}

The dependent variables are logged. All regressions control for year and district fixed effects. Robust standard errors clustered at the medical district level in parentheses

Table 27 Mortality and poverty shocks. Rural areas

\begin{tabular}{llll}
\hline & $(1)$ & $(2)$ & $(3)$ \\
& Maternal mortality & Day 1 mortality & Infant mortality \\
\hline Share poor people in the district & -0.52 & -0.10 & 0.020 \\
& $(0.43)$ & $(0.15)$ & $(0.043)$ \\
Mean dep. var & 3.74 & 1.61 & 4.18 \\
No. of observations & 284 & 284 & 284 \\
$R^{2}$ & 0.31 & 0.41 & 0.59 \\
\hline
\end{tabular}

The dependent variables are logged ratios. All regressions control for year and district fixed effects. Robust standard errors clustered at the medical district level in parentheses 
Table 28 Service provision and poverty levels. No controls for district fixed effects. Rural areas

\begin{tabular}{llll}
\hline & $(1)$ & $(2)$ & $(3)$ \\
& Midwives & Doctors & Vaccinators \\
\hline Share poor people in the district & -0.069 & 0.012 & -0.079 \\
& $(0.051)$ & $(0.051)$ & $(0.048)$ \\
Mean dep. var & 1.88 & 1.28 & 1.76 \\
No. of observations & 284 & 284 & 284 \\
$R^{2}$ & 0.09 & 0.05 & 0.05 \\
\hline
\end{tabular}

The dependent variables are logged. All regressions control for year fixed effects. Robust standard errors clustered at the medical district level in parentheses

Table 29 Mortality and poverty levels. No controls for district fixed effects. Rural areas

\begin{tabular}{llll}
\hline & $(1)$ & $(2)$ & $(3)$ \\
& Maternal mortality & Day 1 mortality & Infant mortality \\
\hline Share poor people in the district & -0.029 & -0.084 & $0.078^{*}$ \\
& $(0.22)$ & $(0.099)$ & $(0.040)$ \\
Mean dep. var & 3.74 & 1.61 & 4.18 \\
No. of observations & 284 & 284 & 284 \\
$R^{2}$ & 0.05 & 0.01 & 0.21 \\
\hline
\end{tabular}

The dependent variables are logged ratios. All regressions control for year fixed effects. Robust standard errors clustered at the medical district level in parentheses

\section{Appendix 5: More results for the urban areas}

Tables 30, 31, 32, 33, 34, 35, 36, 37, 38 show more results for the sample of urban areas.

Table 30 Midwives and other medical personnel. Urban areas

\begin{tabular}{llll}
\hline & $(1)$ & $(2)$ & $(3)$ \\
& Doctors & Dentists & Vaccinators \\
\hline Logged nr of midwives & $0.094^{*}$ & 0.077 & 0.11 \\
& $(0.055)$ & $(0.098)$ & $(0.068)$ \\
Mean dep. var & 2.21 & 1.22 & 1.91 \\
No. of observations & 1190 & 1190 & 1190 \\
No. of districts & 35 & 35 & 35 \\
$R^{2}$ & 0.74 & 0.81 & 0.46
\end{tabular}

The dependent variables are logged. All regressions control for year and district fixed effects as well as district specific time trends. Robust standard errors clustered at the medical district level in parentheses 
Table 31 Medical personnel and mortality. Urban areas

\begin{tabular}{llll}
\hline & $(1)$ & $(2)$ & $(3)$ \\
& Maternal mortality & Day 1 mortality & Infant mortality \\
\hline Logged nr of midwives & 0.28 & -0.024 & 0.010 \\
& $(0.67)$ & $(0.20)$ & $(0.13)$ \\
Logged nr of doctors & -0.18 & 0.40 & -0.070 \\
& $(0.71)$ & $(0.29)$ & $(0.11)$ \\
Logged nr of vaccinators & 0.26 & -0.20 & 0.040 \\
& $(0.71)$ & $(0.17)$ & $(0.079)$ \\
Mean dep. var & 4.68 & 1.99 & 4.31 \\
No. of observations & 1189 & 1189 & 1189 \\
$R^{2}$ & 0.23 & 0.23 & 0.38
\end{tabular}

The dependent variables are logged ratios. All regressions control for year and district fixed effects as well as district specific time trends. Robust standard errors clustered at the medical district level in parentheses

Table 32 Health personnel and placebo causes of death. Urban areas

\begin{tabular}{lllllllll}
\hline & $(1)$ & $(2)$ & $(3)$ & $(4)$ & $(5)$ & $(6)$ & $(7)$ & $(8)$ \\
& Murder & Murder & Accident & Accident & Suicide & Suicide & Other & Other \\
\hline Logged nr of midwives & -0.060 & -0.071 & -0.073 & -0.095 & 0.043 & 0.052 & -7.96 & -6.73 \\
& $(0.12)$ & $(0.12)$ & $(0.12)$ & $(0.14)$ & $(0.23)$ & $(0.24)$ & $(14.5)$ & $(14.8)$ \\
Logged nr of doctors & & 0.0059 & & -0.058 & & -0.040 & -18.7 \\
Logged nr of vaccinators & & $(0.094)$ & & $(0.15)$ & & $(0.20)$ & $(11.3)$ \\
Mean dep. var & & 0.10 & & 0.26 & & -0.053 & 5.16 \\
No. of observations & 0.18 & 0.18 & 2.62 & 2.62 & 0.89 & 0.89 & 0.89 & 0.89 \\
$R^{2}$ & 1189 & 1189 & 1189 & 1189 & 1189 & 1189 & 1190 & 1190 \\
\hline
\end{tabular}

The dependent variables are logged ratios. All regressions control for year and district fixed effects as well as district specific time trends. Robust standard errors clustered at the medical district level in parentheses 
Table 33 Midwives and mortality, dynamic effects. Urban areas

\begin{tabular}{llll}
\hline & $(1)$ & $(2)$ & $(3)$ \\
& Maternal mortality & Day 1 mortality & Infant mortality \\
\hline Logged nr of midwives & -0.19 & -0.54 & -0.15 \\
Lagged midwives & $(1.17)$ & $(0.38)$ & $(0.22)$ \\
& -0.92 & -0.19 & -0.16 \\
2 lags midwives & $(0.99)$ & $(0.24)$ & $(0.23)$ \\
& 0.36 & 0.24 & 0.22 \\
Forward midwives & $(0.98)$ & $(0.19)$ & $(0.20)$ \\
& 0.91 & $0.76^{*}$ & 0.035 \\
2 leads midwives & $(1.11)$ & $(0.40)$ & $(0.23)$ \\
& -0.16 & 0.043 & 0.18 \\
Mean dep. var & $(1.05)$ & $(0.34)$ & $(0.19)$ \\
No. of observations & 4.65 & 1.98 & 4.31 \\
$R^{2}$ & 1049 & 1049 & 1049 \\
\hline
\end{tabular}

The dependent variables are logged ratios. All regressions control for year and district fixed effects as well as district specific time trends. Robust standard errors clustered at the medical district level in parentheses

Table 34 Poverty shocks and provision of medical personnel. Urban areas

\begin{tabular}{llll}
\hline & $(1)$ & $(2)$ & $(3)$ \\
& Midwives & Doctors & Vaccinators \\
\hline Share poor people in the district & $0.083^{* * * *}$ & 0.066 & 0.058 \\
& $(0.028)$ & $(0.050)$ & $(0.070)$ \\
Mean dep. var & 2.54 & 2.21 & 1.91 \\
No. of observations & 1190 & 1190 & 1190 \\
$R^{2}$ & 0.98 & 0.98 & 0.99 \\
\hline
\end{tabular}

The dependent variables are logged. All regressions control for year and district fixed effects as well as district specific time trends. Robust standard errors clustered at the medical district level in parentheses 
Table 35 Mortality and poverty shocks. Urban areas

\begin{tabular}{llll}
\hline & $(1)$ & $(2)$ & $(3)$ \\
& Maternal mortality & Day 1 mortality & Infant mortality \\
\hline Share poor people in the district & 0.36 & 0.12 & -0.014 \\
& $(0.32)$ & $(0.12)$ & $(0.083)$ \\
Mean dep. var & 4.68 & 1.99 & 4.31 \\
No. of observations & 1189 & 1189 & 1189 \\
$R^{2}$ & 0.23 & 0.23 & 0.38 \\
\hline
\end{tabular}

The dependent variables are logged ratios. All regressions control for year and district fixed effects as well as district specific time trends. Robust standard errors clustered at the medical district level in parentheses

Table 36 Service provision and poverty levels. No controls for district fixed effects. Urban areas

Table 37 Mortality and poverty levels. No controls for district fixed effects. Urban areas

\begin{tabular}{llll}
\hline & $(1)$ & $(2)$ & $(3)$ \\
& Maternal mortality & Day 1 mortality & $\begin{array}{l}\text { Infant mortality } \\
\text { Share poor people in the district }\end{array}$ \\
& 0.029 & -0.018 & $0.14^{* * *}$ \\
& $(0.14)$ & $(0.045)$ & $(0.023)$ \\
Mean dep. var & 4.68 & 1.99 & 4.31 \\
No. of observations & 1189 & 1189 & 1189 \\
$R^{2}$ & 0.06 & 0.05 & 0.26
\end{tabular}

The dependent variables are logged ratios. All regressions control for year fixed effects. Robust standard errors clustered at the medical district level in parentheses 


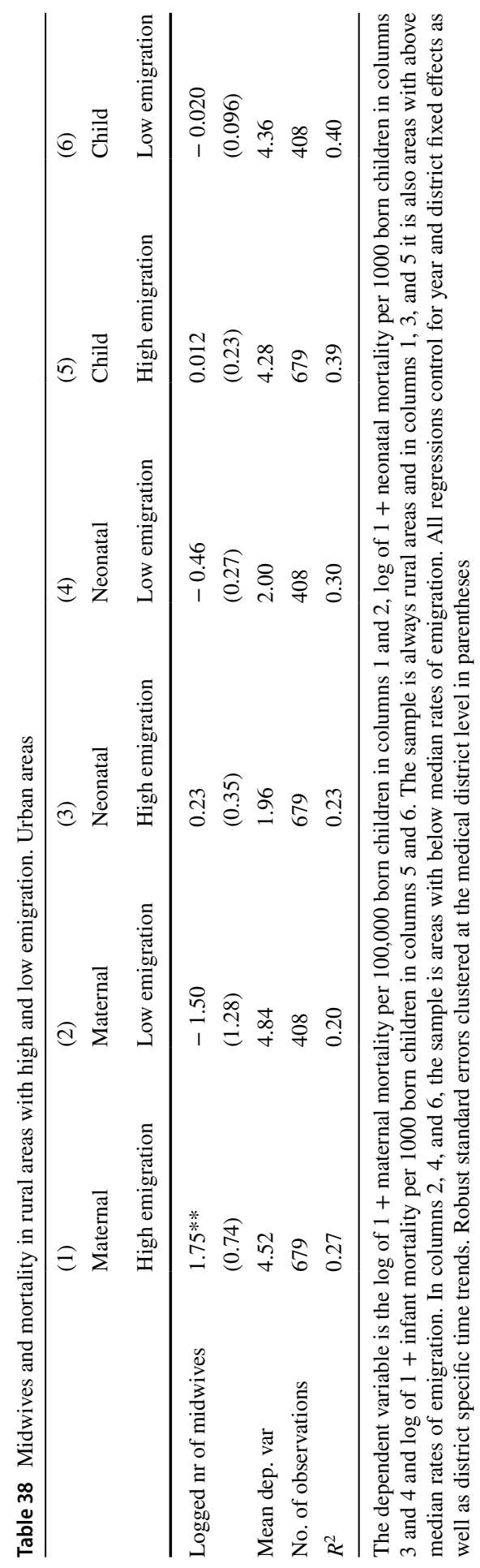




\section{Appendix 6: Source list}

The reports are all titled "Sundhetstilstanden og medicinalforholdene" (spelled "Sundhetstilstanden og medisinalforholdene" from 1916 onwards) and published one or a few years after the year the report refers to. "NOS" refers to "Norwegian Official Statistics." All reports can be downloaded at http://www.ssb.no/a/histstat/ publikasjoner/histemne-02.html.

- 1887: NOS III 95

- 1888: NOS III 116

- 1889: NOS III 143

- 1890: NOS III 162

- 1891: NOS III 185

- 1892: NOS III 222

- 1893: NOS III 252

- 1894: NOS III 274

- 1895: NOS III 290

- 1896: NOS III 317

- 1897: NOS III 327

- 1898: NOS IV 1

- 1899: NOS IV 27

- 1900: NOS IV 55

- 1901: NOS IV 77

- 1902: NOS IV 103

- 1903: NOS IV 128

- 1904: NOS V 23

- 1905: NOS V 55

- 1906: NOS V 72

- 1907: NOS V 98

- 1908: NOS V 122

- 1909: NOS V 152

- 1910: NOS V 181

- 1911: NOS V 216

- 1912: NOS VI 19

- 1913: NOS VI 56

- 1914: NOS VI 94

- 1915: NOS VI 133

- 1916: NOS VI 186

- 1917: NOS VII 3

- 1918: NOS VII 58

- 1919: NOS VII 108

- 1920: NOS VII 138 
Acknowledgements We would like to thank participants at workshops and conferences as well as other colleagues for comments and suggestions. We thank Tora Knutsen, Emil Kordahl, Adam Reiremo, and Edda Torsdatter Solbakken for excellent research assistance. We are grateful for financial support from the Røwde foundation and UiO:Nordic. This paper is part of the research activities at the centre of Equality, Social Organization, and Performance (ESOP) at the Department of Economics at the University of Oslo.

Funding Open access funding provided by University of Oslo (incl Oslo University Hospital)..

Open Access This article is licensed under a Creative Commons Attribution 4.0 International License, which permits use, sharing, adaptation, distribution and reproduction in any medium or format, as long as you give appropriate credit to the original author(s) and the source, provide a link to the Creative Commons licence, and indicate if changes were made. The images or other third party material in this article are included in the article's Creative Commons licence, unless indicated otherwise in a credit line to the material. If material is not included in the article's Creative Commons licence and your intended use is not permitted by statutory regulation or exceeds the permitted use, you will need to obtain permission directly from the copyright holder. To view a copy of this licence, visit http://creativecommons.org/licen ses/by/4.0/.

\section{References}

Abramitzky R, Boustan LP, Eriksson K (2012) Europe's tired, poor, huddled masses: self-selection and economic outcomes in the age of mass migration. Am Econ Rev 102:1832-1856

Anderson DM, Brown R, Charles KK, Rees DI (2020) Occupational licensing and maternal health: evidence from early midwifery laws. J Polit Econ 128:4337-4383

Andersson T, Högberg U, Bergström S (2000) Community-based prevention of perinatal deaths: lessons from nineteenth-century Sweden. Int J Epidemiol 29:542-548

Andrews K, Brouillette D, Brouillette R (2008) Mortality, infant. In: Haith MM, Benson JB (eds) Encyclopedia of infant and early childhood development. Academic Press, San Diego, pp 343-359

Backer J (1961) Dødeligheten og dens årsaker i Norge 1856-1955, Samfunnsøkonomiske studier. Statistisk sentralbyrå, Oslo, p 10

Bailey MJ, Goodman-Bacon A (2015) The war on poverty's experiment in public medicine: community health centers and the mortality of older Americans. Am Econ Rev 105:1067-1104

Cesur R, Güneş PM, Tekin E, Ulker A (2017) The value of socialized medicine: the impact of universal primary healthcare provision on mortality rates in Turkey. J Public Econ 150:75-93

de Brouwere V (2007) The comparative study of maternal mortality over time: the role of the professionalisation of childbirth. Soc Hist Med 20:541-562

Deaton A (2013) The great escape. Health, wealth, and the origins of inequality. Princeton University Press, Princeton

Edvinsson S, Gardarsdóttir 1, Thorvaldsen G (2008) Infant mortality in the Nordic countries, 1780-1930. Contin. Change 23:457-485

Farstad A (2016) På liv og død. Distriktsjordmødrenes historie. Samlaget, Oslo

Frankenberg E, Thomas D (2001) Women's health and pregnancy outcomes: do services make a difference? Demography 38:253-65

Frankenberg E, Suriastini W, Thomas D (2005) Can expanding access to basic healthcare improve children's health status? Lessons from Indonesia's "Midwife in the Village" programme. Popul Stud 59:5-19

Högberg U, Wall S, Broström G (1986) The impact of early medical technology on maternal mortality in late 19th century Sweden. Int J Gynecol Obstet 24:251-261

Kjærheim K (1987) Mellom kloke kvinner og kvitkledde men, Jordmorvesenet på 1800-tallet. Samlaget, Oslo

Lazuka V (2018) The long-term health benefits of receiving treatment from qualified midwives at birth. J Dev Econ 133:415-433 
Lazuka V, Quaranta L, Bengtsson T (2016) Fighting infectious disease: evidence from Sweden 18701940. Popul Dev Rev 42:27-52

Liebert H, Mäder B (2020) Physicians and the production of health: returns to health care during the mortality transition. Harvard University, Mimeo, Harvard

Loudon I (1992) Death in childbirth. An international study of maternal care and maternal mortality 1800-1950. Clarendon Press, Oxford

Loudon I (2000) Maternal mortality in the past and its relevance to developing countries today. Am J Clin Nutr 72:241S-6S

Modalsli J (2018) The regional dispersion of income inequality in nineteenth-century Norway. Explor Econ Hist 67:62-79

Moehling CM, Thomasson MA (2012) The political economy of saving mothers and babies: the politics of state participation in the Sheppard-Towner program. J Econ Hist 72:75-103

Moehling CM, Thomasson MA (2014) Saving babies: the impact of public education programs on infant mortality. Demography 51:367-386

Norwegian Centre for Research Data (2017) Kommunedatabasen [Municipal database]. https://trygg.nsd. uib.no/kdbbin/kdb_start.exe

Østby G, Urdal H, Tollefsen AF, Kotsadam A, Belbo R, Ormhaug C (2018) Organized violence and institutional child delivery: micro-level evidence from sub-Saharan Africa. Demography 1989-2014:1-22

Pettersson-Lidbom P (2015) Midwives and maternal mortality: evidence from a midwifery policy experiment in Sweden in the 19th century. Mimeo

Pitkänen KJ (2002) Early mortality decline in Norway in comparative perspective. In: Hubbard WH, Pitkänen K, Schlumbohm J, Sogner S, Thorvaldsen G, van Poppel F (eds) Historical studies in mortality decline. CAS, Norwegian Academy of Science and Letters, Oslo, pp 11-22

Sandvik H (2000) Distriktslegen (1836-1984). Tidsskrift for Den norske legeforening 120:3160-1

Schiøtz A (2003) Folkets helse-landets styrke 1850-2003, volume 2 of Det offentlige helsevesen i Norge 1603-2003. Universitetsforlaget, Oslo

Thomasson MA, Treber J (2008) From home to hospital: the evolution of childbirth in the United States, 1928-1940. Explor Econ Hist 45:76-99

Thorvaldsen G (2002) Rural infant mortality in nineteenth century Norway. In: Hubbard WH, Pitkänen K, Schlumbohm J, Sogner S, Thorvaldsen G, van Poppel F (eds) Historical studies in mortality decline. CAS, Norwegian Academy of Science and Letters, Oslo, pp 43-78

Thorvaldsen G (2008) Was there a European breastfeeding pattern? Hist Fam 13:283-295

Triyana M (2016) The effects of Indonesia's "Midwife in the Village" programme 10 years post-launch. Popul Stud 70:365-376

World Health Organization (2019) Trends in maternal mortality 2000 to 2017: estimates by WHO. UNICEF, UNFPA, World Bank Group and the United Nations Population Division, Geneva

Wüst M (2012) Early interventions and infant health: evidence from the Danish home visiting program. Labour Econ 19:484-495

Publisher's Note Springer Nature remains neutral with regard to jurisdictional claims in published maps and institutional affiliations. 